\title{
Investigation Break Down Voltages for High Density Polyethylene Cables Using Multiple Regression
}

\author{
Hussein M. Nabil, Loai S. Nasrat, and Salah M. Kamel
}

\begin{abstract}
This paper illustrated the electrical characteristic of High Density Polyethylene (HDPE) by adding an alumina trihydrate (ATH)filler At concentrations vary from $0 \%$ to $40 \%$.

Multiple Regression Analysis (MRA) was used to find the best suitable curve between the percentages of ATH filler and the Break down Voltages $(\mathrm{kV} / \mathrm{mm})$.
\end{abstract}

Index Terms - HDPE, ATH, Break down Voltages, Multiple Regression Analysis.

\section{INTRODUCTION}

HDPE cable sheathing is a type of macromolecular polymer. Observations and researches regarding its dynamic properties, especially under fatigue loading, are the key to understanding the durability of cables as well as that of entire cable-stayed bridges, and these should receive greater attention. In general, because of the effects of and competition between cracking and the shear zone within macromolecular materials, microscopic expansion mechanisms are highly complicated [5]-[7]. Under fatigue loading, the evolution of fatigue damage in HDPE materials is typically as follows. As micro cracks develop and propagate, their number and density reach a critical value, at which time one or more neighboring micro cracks begin to form fatigue cracks. Because of the concentration of stress, new micro cracks form at the peaks of the cracks and develop further under the effect of cyclical stress. Multiple Regression Analysis is a form of predictive modeling technique which investigates the relationship between a dependent and independent variable using the relationship between variables to find the best fit line or the regression equation

\section{EXPERIMENTAL PROCEDURE}

\section{A. Specimens}

Specimens were prepared from HDPE with different concentrations of ATH according to ASTM 149.

$>$ Break Down Voltage test: The ability of the insulating material to withstand maximum electrical stress without break down.

Sets of blend samples have been prepared under Four weather testing conditions are performed such as (Dry - Wet - Salty Wet - Acid).

\section{B. High Voltage Laboratory Set up}

\section{High Voltage auto transformer}

Fig. 1 illustrates the A.C high voltage obtained from a single phase high voltage auto transformer (Terco type HV 9105) $100 \mathrm{KV}-5 \mathrm{KVA}$ - $50 \mathrm{~Hz}$, has been used which is supplied by the main board from its primary Fig. 1 . The main board is controlled by variac $(0-220 \mathrm{~V})$.

A resistor of $2.8 \mathrm{M} \Omega$ was connected to the secondary winding of the high voltage testing transformer in order to protect the high voltage transformer from the high current during the test.

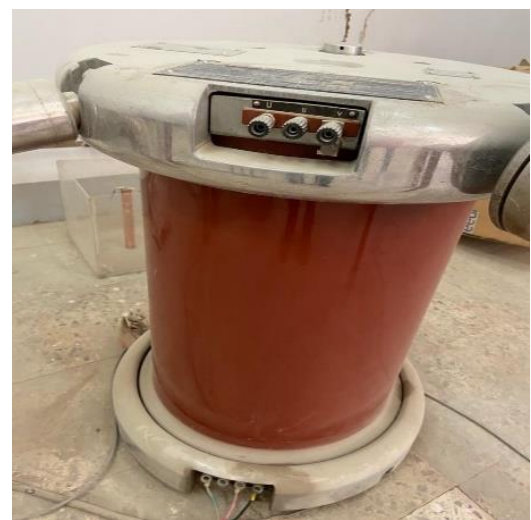

Fig. 1. High voltage autotransformer.

\section{Test Electrodes}

During this study two identical electrodes are used. Each of them has $5 \mathrm{~mm}$ diameter, made from copper brass.

Fig. 2 shows the electrodes and the Specimen between them.

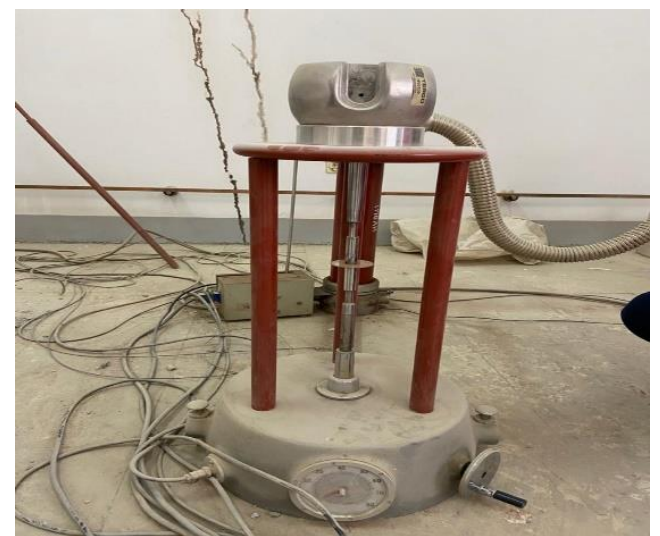

Fig. 2. Cylindrical electrode.

Salah M. Kamel, Associate Professor, Dep. of Electrical Engineering, Faculty of Engineering, Aswan University, Egypt. (e-mail: Skamel@aswu.edu.eg) 


\section{Specimen Measure}

Each specimen has $50 \mathrm{~mm}$ diameter and $1 \mathrm{~mm}$ thickness.

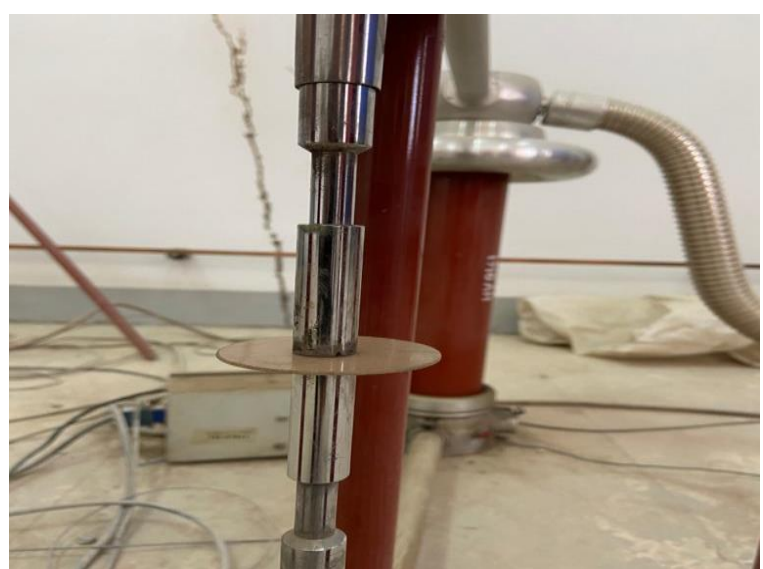

Fig. 3. Sample test.

\section{Control Deck}

Fig. 4 illustrate components of Control Deck consisting of the main board is controlled by variac $(0-220 \mathrm{~V})$ and indicators lamps for primary side and secondary side of H.V autotransformer and Digital screen showing measured results.

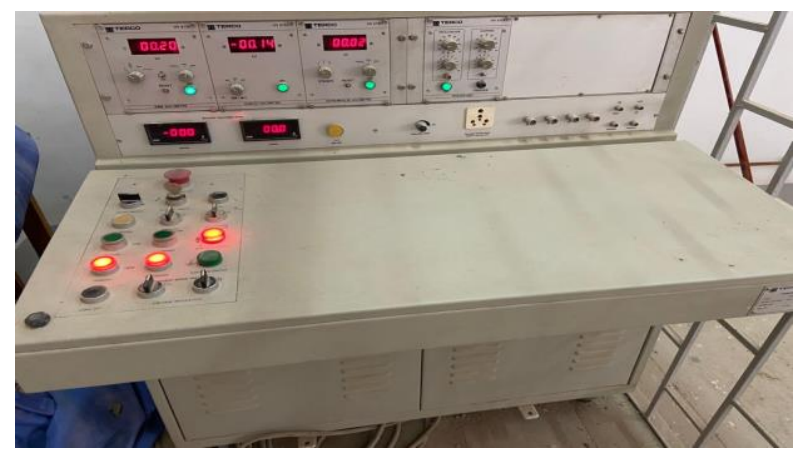

Fig. 4. Control Deck of the H.V laboratory.

\section{EXPERIMENTAL RESULTING}

The experimental results are discussed; the results which have been obtained are analyzed.

Many factors have been studied in the present work. These are:

1. Wet condition effect

2. Dry condition effect;

3. Salty Wet condition effect;

4. Acid condition effect.

Table I shows the results of the average break down voltage $(\mathrm{kV} / \mathrm{mm})$ for mix specimens (HDPE/ATH) under different condition.

Fig. 5 shows the Comparison between break down voltage for High Density Polyethylene with (ATH) Fillers under (dry, wet, salty Wet and acid) Conditions.

It can be cleared that, increasing weight percentage of ATH improves the break down voltage of the blends. The break down voltage decreased, at wet, salinity and acid conditions. Because of the water and salinity caused leakage current in addition to at acid conditions, causing chemicals to attack the break down voltage.

- When the percentage of ATH is being increased with $10 \%, 20 \%, 30 \%$ and $40 \%$, the reduction percentage of the value of break down voltage from dry to wet condition is $15.6 \%, 12.2 \%, 9.7 \%$ and $14.5 \%$ respectively.

- When the percentage of ATH is being increased with $10 \%, 20 \%, 30 \%$ and $40 \%$, the reduction percentage of the value of break down voltage from dry to salinity condition is $23.5 \%, 21.1 \%, 16.7 \%$ and $21.3 \%$ respectively.

- When the percentage of ATH is being increased with $10 \%, 20 \%, 30 \%$ and $40 \%$, the reduction percentage of the value of break down voltage from dry to Acid condition is $32.1 \%, 29.3 \%, 23.3 \%$ and $29 \%$ respectively.

TABLE I: RESULTS OF BREAK DOWN VOLTAGE UNDER DIFFERENT CONDITIONS

\begin{tabular}{ccccc}
\hline FTH & $\begin{array}{c}\text { Average } \\
\text { break down } \\
\text { voltage } \\
(\mathrm{kV} / \mathrm{mm}) \text { in } \\
\text { dry condion }\end{array}$ & $\begin{array}{c}\text { Average break } \\
\text { down voltage } \\
(\mathrm{kV} / \mathrm{mm}) \text { in } \\
\text { wet condion }\end{array}$ & $\begin{array}{c}\text { Average } \\
\text { break down } \\
\text { voltage } \\
(\mathrm{kV} / \mathrm{mm}) \text { in } \\
\text { Salty Wet } \\
\text { condion }\end{array}$ & $\begin{array}{c}\text { Average } \\
\text { break down } \\
\text { voltage } \\
(\mathrm{kV} / \mathrm{mm}) \text { in } \\
\text { Acid condion }\end{array}$ \\
\hline 0 & 22.0 & 18.3 & 14.9 & 13.6 \\
10 & 24.3 & 20.5 & 18.6 & 16.5 \\
20 & 27.0 & 23.7 & 21.3 & 19.1 \\
30 & 31.7 & 28.6 & 26.4 & 24.3 \\
40 & 28.6 & 24.5 & 22.5 & 20.3 \\
\hline
\end{tabular}

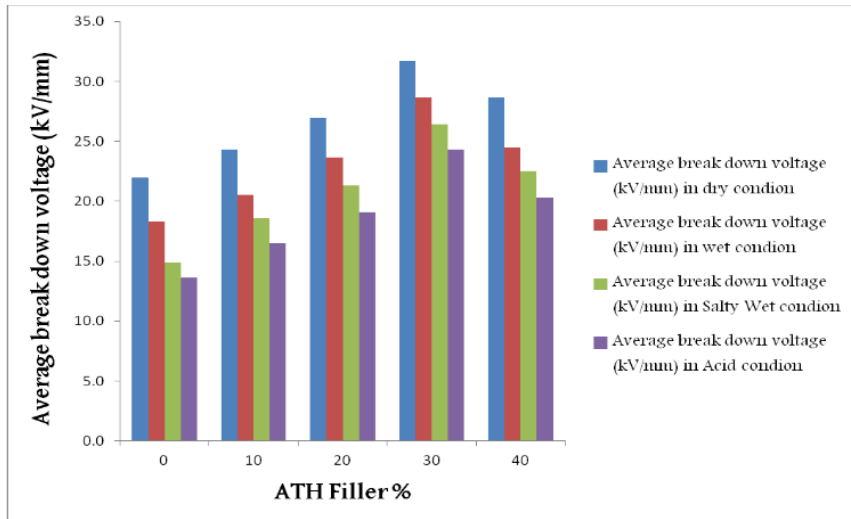

Fig. 5. Break down voltage for (HDPE/ATH) blends under (dry, wet, salty wet and acid) Conditions.

From the previous it is clear that the best value of specimen is at $(30 \% \mathrm{ATH})$ under different weather testing conditions. break down voltage was improved by increasing the content of ATH in HDPE sample had the highest break down voltage of:

> $31.7 \mathrm{kV} / \mathrm{mm} \quad(44.5 \%$ improvement $)$ under dry condition.

$>28.6 \mathrm{kV} / \mathrm{mm} \quad(56.5 \%$ improvement $)$ under wet condition.

$26.4 \mathrm{kV} / \mathrm{mm}$ (77\% improvement) under salty wet condition.

$>24.3 \mathrm{kV} / \mathrm{mm}(78.5 \%$ improvement $)$ under acid condition. 


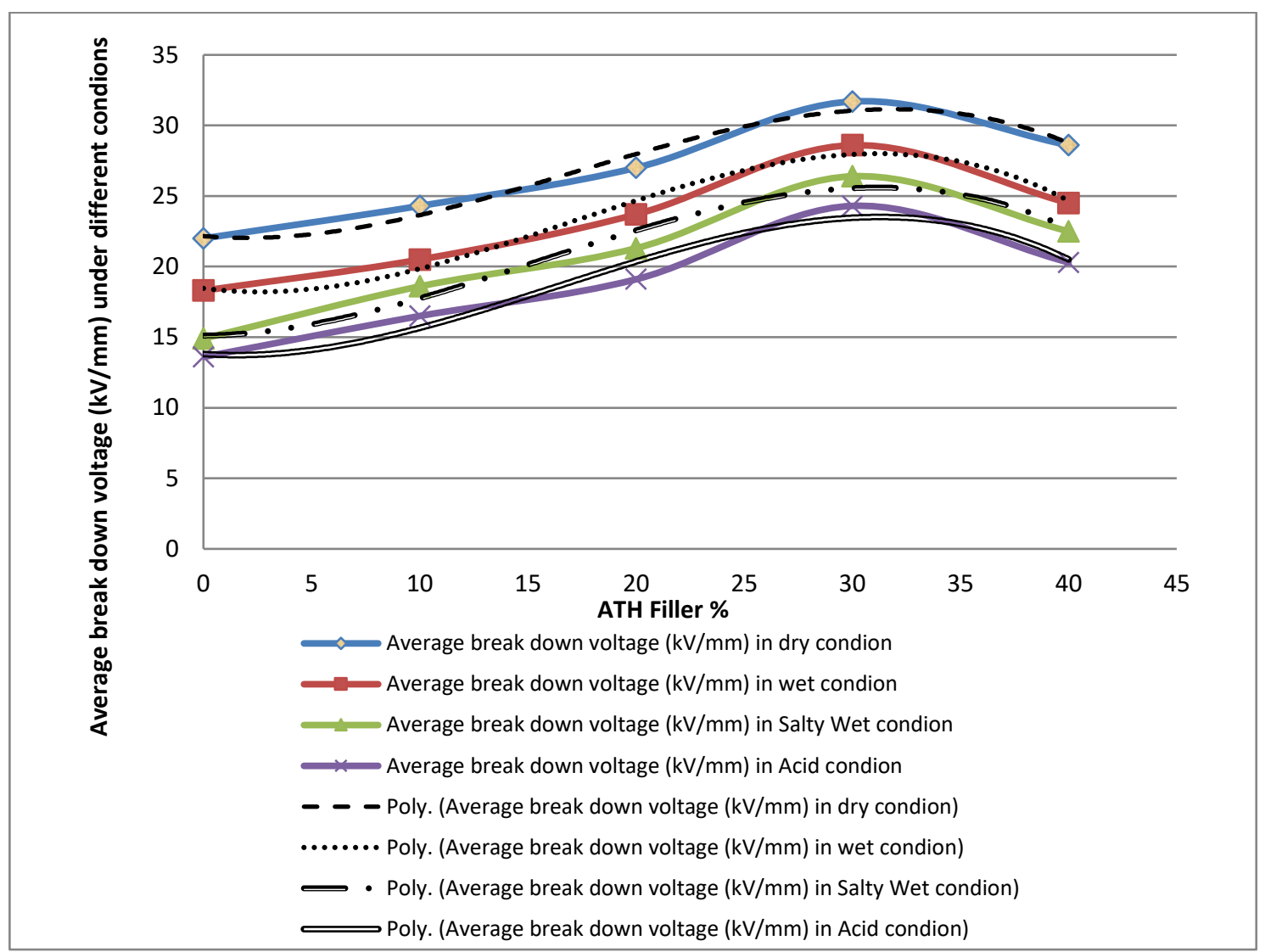

Fig. 6. Regression analysis results of break down voltage for (HDPE/ATH) blends under (dry, wet, salty Wet and acid) Conditions.

From the calculation of regression analysis for the data obtained can be represented by 3rd degree polynomial equation at (dry, wet, salty Wet and acid) Conditions respectively as follows:

$$
\begin{gathered}
y=-0.0007 x^{3}+0.0347 x^{2}-0.1302 x+22.163 \\
y=-0.0008 x^{3}+0.0422 x^{2}-0.2002 x+18.463 \\
y=-0.0007 x^{3}+0.0309 x^{2}+0.0224 x+15.111 \\
y=-0.0007 x^{3}+0.0365 x^{2}-0.1058 x+13.81
\end{gathered}
$$

where

$\mathrm{Y}$ is the break down voltage;

$\mathrm{X}$ is filler percentage $\%(0,10,20,30$ and $40 \%)$;

$\mathrm{A}$ is the constant;

`B, C, D are the coefficient of filler percentage. Coefficients.

\section{CONCLUSION}

1. The best percentage of filler to improve electric characteristic for HDPE under several weather conditions is $30 \%$.

2. Exposure the samples to acid condition affected negatively on its break down voltage.

3. Salty Wet condition resulted in decreasing the break down voltage due to $\mathrm{NaCl}$ solution absorption.

4. The break down voltage decreased in wet condition as compared with those in dry condition because of hydrophobicity of polymeric material inhibits the formation of a continuous water film and therefore suppresses the leakage current thereby improving its contamination break down voltage performance.
5. The lowest values of break down voltage at acid condition. This is because of the Chemical material attack most frequently leads to embrittlement or brittle failure.

6. Electrical characteristics have decreased at higher salinities and moisture.

7. The optimization methods are more accurate than the laboratory method, But its complementary methods not separate methods.

\section{ACKNOWLEDGMENT}

The authors would like to thank the staff of High Voltage Laboratory, Electrical Engineering Dept. Aswan University and National Research Center, Polymers \& Pigments Dept. where most of the sample's preparation and experimental work were carried out.

\section{REFERENCES}

[1] I. A. Metwally, "High-voltage power cables plug into the future," IEEE Potentials, vol. 27, no. 1, pp. 18-25, 2008.

[2] J. Rohan. Lucas "High voltage engineering", 2001.

[3] W. Thue, Electrical Power Cable Engineering, Second Editions," CRC Press Inc., Second edition, Chapters 1, 2, 5, 2003.

[4] Y. J. Jeng and A. Martin' "Residuals in Multiple Regression Analysis", June 13, 1985.

[5] A. Colin Cameron "Multiple Regression with excel", Dept. of Economics, Univ. of Calif. - Davis, January 2009

[6] A. T. Mohamed" Thermal experimental verification on effects of nanoparticles for enhancing electric and dielectric performance of polyvinyl chloride" Measurement 89 (2016) 28-33.

[7] A. Aman, M.M. Yaacob, M.A. Alsaedi, Kh.A. Ibrahim, Polymeric composite based on waste material for high voltage outdoor application, IJEPES Int. J. Electr. Power Energy Syst. 45 (1) (2013) 346-352.

[8] J.K. Nelson and Y. Hu, "Nanocomposite Dielectrics - Properties and Implications", J. Phys. D: Appl. Phys., Vol. 38, pp. 213-222, 2005. 
[9] T.J. Lewis, "Nanometric Dielectrics", IEEE Trans. Dielectr. Electr. Insul., Vol. 15, pp. 812-825, 1994.

[10] J.K. Nelson and Y. Hu, "Nanocomposite Dielectrics - Properties and Implications", J. Phys. D: Appl. Phys., Vol. 38, pp. 213-222, 2005.

[11] R. A. Bernstorf, R. K. Niedermier, D. S. Winkler "Polymer Compounds Used in High Voltage Insulators" Chemical book, EU 1407-HR1.

[12] S. L. Uppal and S. Rao, "Electrical Power Systems", Fifteenth edition, Book, 2005

[13] Zazoum et al., ISRN Nano-Materials (2014) 9, Article ID 612154

[14] O. Gouda, A. Thabet, Y.A. Mubarak, M. Samir, Int. J. Electr. Eng. Inf. $6(2014) 1-12$

[15] John O. Rawlings, Sastry G. Pantula, David A. Dickey "Applied Regression Analysis: A Research Tool, Second Edition" on line books, 12 July 2012.

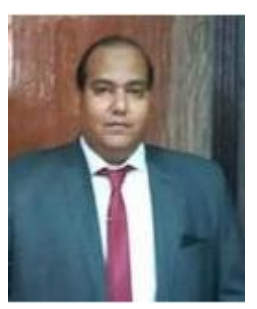

Hussein Mohamed Nabil was born in Aswan, Egypt on 22th September 1990. He received the B.Sc. (FEE) Electrical Engineering degree in 2012 from the Higher Institute of Engineering at Elshorouq Academy, Egypt and currently pursuing "master of Electrical Engineering" from Faculty of Engineering, Aswan University, Egypt. He is working at central agency for reconstruction, housing ministry in Aswan government, Egypt as Electrical Engineer from 2014 till now. His research interests lie in the areas of analysis and developing electrical engineering models and applications, investigating insulating materials via blending different types of polymers for usage in industrial branch and the relationship with electrical properties of industrial polymers.

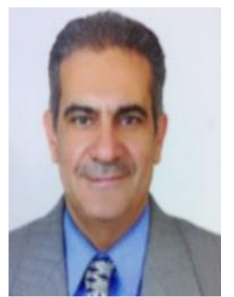

Dr. Loai Nasrat is a professor at Aswan University, Faculty of Eng., Elect. P\&M Department. He has been actively involved in both basic and applied research in the area of HV engineering. His research interests include $\mathrm{HV}$ insulators, polymeric materials, $\mathrm{HV}$ cables insulations and environmental studies.

Author and co-author of more than 100 papers on HV polymeric insulating materials, published in technical journals and proceedings of national and international conferences.

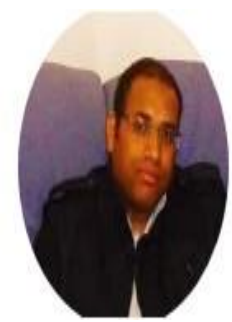

Dr. Salah Kamel is an associate Professor, Dep. of Electrical Engineering, Faculty of Engineering, Aswan University.

Author and co-author of more than 50 papers on HV polymeric insulating materials, Power system, Renewable energy, and Smart grid, published in technical journals and proceedings of national and international conferences. 